\title{
Los primeros 50 años de la Facultad de Estomatología de la Universidad Peruana Cayetano Heredia
}

\author{
The First 50 years of the Stomatology Faculty Peruvian University Cayetano Heredia
}

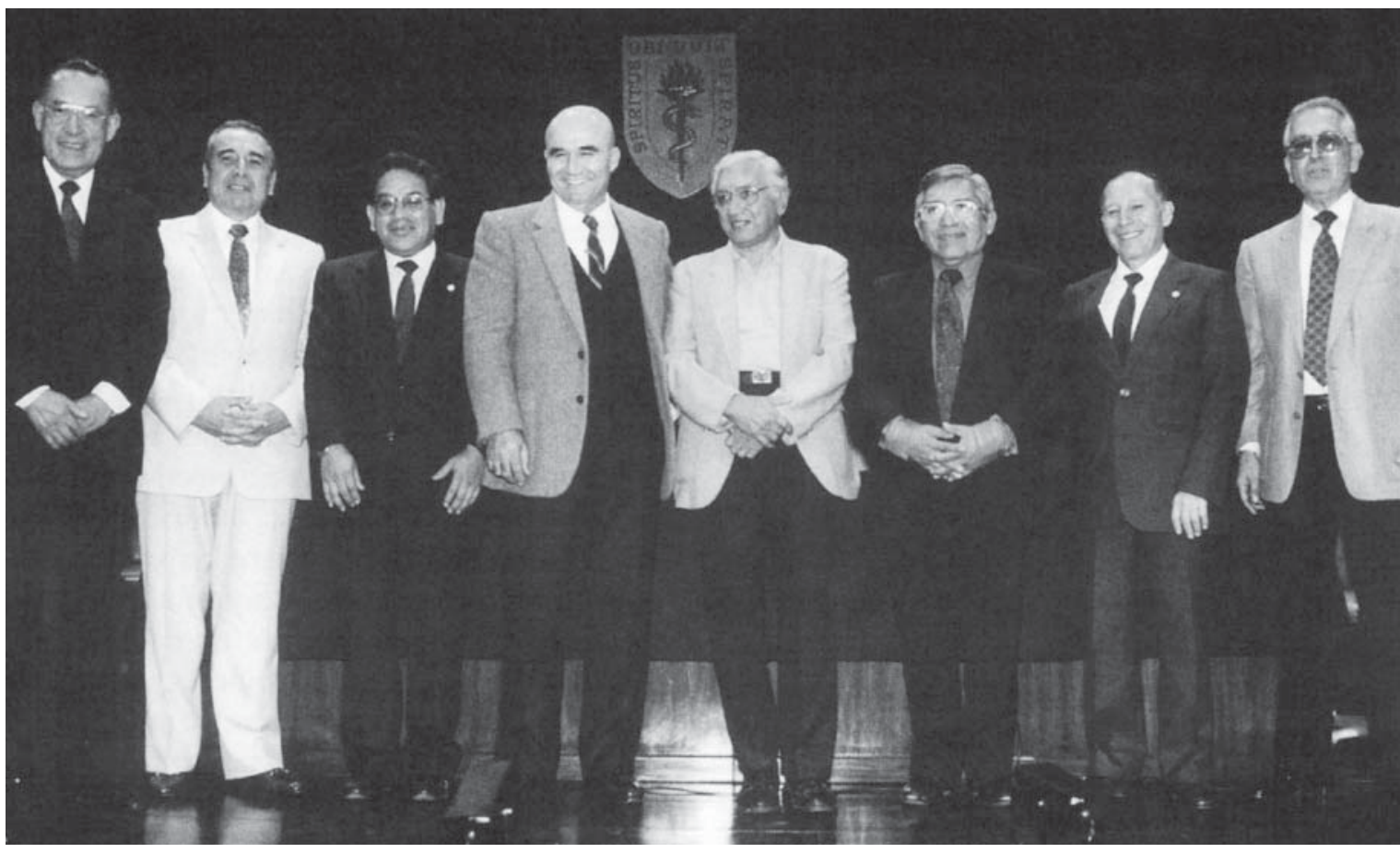

Fundadores de la Facultad de Estomatología de la Universidad Peruana Cayetano Heredia. De izq. a der. los doctores: David Loza Fernández, Hernán Villena Martínez, Wilson Delgado Azañero, Guillermo Zárate

Figueroa, Juan Palacios Anicama, Juan Bernal Morales y Ramón Castillo Mercado.

Corría el año 1964, año de la enseñanza gratuita cuando el Dr. Roberto Beltran propone a las autoridades de la Universidad Peruana Cayetano Heredia la creación de una escuela para auxiliares de Odontología. Entre los años 1967 y 1969 se amplió la propuesta impulsando el proyecto de creación de la Facultad de Estomatología de la Universidad Peruana Cayetano Heredia. El 11 de diciembre de 1969, el Dr. Nicanor Carmona, Secretario General de la Universidad Peruana Cayetano Heredia, confirma que el Consejo Directivo acuerda la creación del Programa Académico de Estomatología. A partir de 1970 el Dr. Beltran junto con otros siete odontólogos diseñaron el currículo para la carrera de Estomatología basado en las necesidades de salud oral de la comunidad. Se crea el Departamento de Odontología conformado por los doctores Roberto Beltran, Juan Bernal, Ramón Castillo, Wilson Delgado, David Loza, Juan Palacios, Hernán Villena y Guillermo Zárate quienes serían posteriormente conocidos como los Fundadores de la Facultad de Estomatología de la Universidad Peruana Cayetano Heredia. En 
Octubre de 1970 se recibió el donativo de la Fundación Kellogg. A partir de ese momento, lo que ha caracterizado a nuestra Facultad es el espíritu innovador plasmado a través de la formación del equipo de salud integrado por el estomatólogo, asistenta dental y técnico dental, construcción de la primera clínica dental en el Perú diseñada especialmente para Estomatología, implementación del trabajo clínico a cuatro manos, sistema académico basado en competencias, internado rural, internado hospitalario, clínicas intensivas e integrales, programas de pre-docencia, creación de programas de especialización y de grado, revista estomatológica herediana, centro quirúrgico odontológico referente de la región, historia clínica digitalizada, centro de simulación en realidad virtual, rotaciones internacionales y la doble titulación profesional.

Durante todo el tiempo de funcionamiento de la Facultad de Estomatología se han graduado odontólogos, técnicos dentales y asistentas dentales. Sin lugar a dudas más que el número de graduados, el logro más trascendental es que todos ellos han recibido durante su formación la tradicional exigencia académica, sello distintivo de nuestra casa de estudios.

No en vano nuestra Facultad cuenta con certificados de acreditación internacional otorgado por la CNA de Colombia, certificado de acreditación nacional otorgado por la CONEAU y certificados ISO 9001: 2008 de nuestras clínicas docentes de San Martin de Porres y San Isidro.

Estos 50 años han sido un cúmulo de nuevas experiencias en Estomatología donde lo único constante ha sido la innovación y el cambio.

Mg. Hugo Ronquillo-Herrera ${ }^{1, a}$ 